Lingüística

Vol. 33-2, diciembre 2017: 9-31

ISSN 2079-312X en línea

DOI: $10.5935 / 2079-312 X .20170015$

\title{
ETIMOLOGÍA POPULAR Y ETIMOLOGÍA CIENTÍFICA: EL CASO DE ATAWALLPA WALLPA PARA DESIGNAR AL GALLO EN EL MUNDO ANDINO Y AMAZÓNICO
}

\author{
FOLK ETYMOLOGY AND MODERN ETYMOLOGY: THE CASE OF ATAWALLPA \\ WALLPA FOR DESIGNATINGTHE ROOSTER IN THE ANDEAN AND AMAZONIAN \\ WORLD
}

\author{
Rodolfo Cerrón-Palomino \\ Pontificia Universidad Católica del Perú \\ rcerron@pucp.pe
}

\begin{abstract}
"[...] no cualquiera cosa que se halla con nombre propio de la lengua de alguna nación de indios se ha de juzgar por sólo este indicio ser propia desta tierra; porque puede ser que le hayan puesto el tal nombre los indios por alguna semejanza y afinidad que la tal cosa tenga con aquello que propiamente significaba el tal nombre".

Cobo ([1653] 1956: IV, I, 154)
\end{abstract}

\section{Resumen}

Pese a conocerse que los habitantes del antiguo país de los incas desconocían el ave de corral, según nos refieren las crónicas, no han faltado quienes sostengan lo contrario, basándose en la supuesta existencia del nombre indígena que lo estaría designando. Y así se afirma que la palabra quechua <atawallpa>, coincidente con el nombre del soberano emboscado en Cajamarca en 1532, o su forma abreviada <wallpa>, vendría a ser también, por alguna razón que no suele explicarse, o se lo hace antojadizamente, la designación nativa original de la gallinácea. En el colmo de esta práctica seudo-erudita y desinformada no ha faltado quien traduzca el nombre del soberano inca como "Feliz gallo", pero igualmente se ha caído en el error de reconstruirlo, anacrónicamente, para el proto-quechua. Pues bien, en el presente trabajo buscaremos demostrar, siguiendo la advertencia señalada por el enciclopédico historiador citado en nuestro epígrafe, que el nombre nativo del gallo se deriva, formalmente, del antropónimo del mencionado monarca, cuyo étimo remonta a *atawwallpa, y a partir del cual se explican las numerosas variantes que registra la designación del gallo no solo en las lenguas andinas sino también en buena parte de las amazónicas. Como se verá, la propuesta ofrecida le hace una concesión esta vez a la etimología popular, o ingenua, por lo demás tan vapuleada en los estudios de corte etimológico científico. Finalmente, demostraremos que el origen ulterior del nombre es de filiación puquina, la tercera lengua general del antiguo Perú. 
Palabras claves: etimología, antroponimia, homofonía, onomatopeya, incremento silábico, puquina.

In spite of the fact that the former inhabitants of ancient Peru didn't know the chicken, as the chronicles inform us, there were those who have maintained the opposite view, based on the supposed existence of the indigenous word that names it. Thus, it is maintained that the Quechua Word <atawallpa>, coincident with the name of the last king of the Inkas, ambushed in Cajamarca in 1532 , or its shortened form <wallpa>, could be also, for some reason which is not explained, unless willfully, the original native designation of the avian. Summing up this pseudo-erudite practice, not only there has been someone who glossed the name of the Inka sovereign as "Happy rooster", but also it has been anachronically postulated for the Proto-Quechua lexicon. That being so, in the present paper we'll seek to demonstrate that, following the advertisement made by the historian cited in our epigraph, that the native name of the avian is derived, formally, from the anthroponym of the mentioned sovereign, its etymon going back to *ataw wallpa, from which the numerous variants that the designation of the rooster has, not only in the Andean languages but also in a good number of the Amazonian languages, are derived. As it will be shown, the postulation advanced gives there as on this time to folk etymology, or so to speak, to naïve etymology, otherwise discredited in the realm of the scientifically oriented studies of the discipline. Finally, we'll try to prove that the ulterior origin of the name goes back to Puquina, the third general language of ancient Peru.

Keywords: etymology, anthroponymy, homophony, onomatopoeya, syllabic increment, Puquina.

Recibido: $23 / 11 / 2016$

Aceptado: $11 / 01 / 2017$

\section{El nombre del gallo/ gallina en lengua indígena.}

El nombre aparentemente nativo del gallo o de la gallina aparece consignado desde las primeras fuentes lexicográficas del quechua y del aimara, y se lo registra tanto en su versión recortada como en su forma enteriza. En efecto, el Nebrija indiano lo consigna en ambas versiones, distinguiendo entre <guallpa> 'gallo' (cf. Santo Tomás [1560] 1994: I, fols. $61 \mathrm{v}$, II: 133v) y <atapallipa> <atapáliba> 'gallina' (II, fol. $61 \mathrm{v}$ y fol. 111 , respectivamente). ${ }^{1}$ Que la primera es una forma abreviada de la segunda, pese a la distinta apariencia de esta, lo podemos comprobar fácilmente consultando el vocabulario quechua del hasta ayer referido como Anónimo, y hoy identificado

\footnotetext{
${ }^{1}$ Las diferencias entre <atapallipa > y <atapáliba>, por un lado, y entre estas y <atahuallpa>, por el otro, serán explicadas en la sección siguiente.
} 
como Blas Valera, quien registra 'gallo' como <huallpa> y 'gallina' como <atahuallpa> (cf. Anónimo [1586] 2014: I, 53;II, 103). ${ }^{2}$ Este mismo lexicógrafo parece sugerirnos que la distinción formal aparente entre ave macho y hembra no sería general en el quechua, ya que en la variedad llamada chinchaisuya <huallpa> valía también para 'gallina'. Que en verdad no había diferencia en la designación ${ }^{3}$ nos lo prueba el tercer lexicógrafo del quechua, quien emplea el vocabulario de Blas Valera como plantilla para elaborar el suyo, al consignar 'gallina' como <atahuallpa> y 'gallo' como <Vrccoatahuallpa> (Gonçález Holguín [1608] 1952: II, 531), es decir anteponiéndole el adjetivo distinguidor <vrcco>, o sea /urqu/ 'macho'. ${ }^{4} \mathrm{La}$ misma distinción la encontramos en el aimara, pues el primer lexicógrafo de esta lengua, compañero de orden de Gonçález Holguín, consigna <atahuallpa> 'gallina' y <Vrcoatahuallpa > 'gallo' (cf. Bertonio [1612] 1984: II, 27). ${ }^{5}$

Ahora bien, la designación inicial del gallo y de la gallina, en sus dos versiones, no solo aparece registrada en las lenguas andinas mayores habladas en el territorio peruano actual, así como en las de carácter regional y local, todas ellas ya desaparecidas (por ejemplo en la culle y en la puquina), ${ }^{6}$ sino también en las que se hablaban, o se hablan aún, en todo el territorio anteriormente cubierto por el imperio de los incas, incluyendo el de las etnias amazónicas que trabaron contacto con el imperio incaico, tal como lo demostró, en su estudio pionero, el conocido etnógrafo sueco Erland Nordenskiöld (1922: 22-23). En efecto, reflejos perfectamente identificables de ambas versiones, pero sobre todo de la enteriza (por ejemplo, <atawari>, en el cocama, y <achauripa>, en el piro), se encuentran en lenguas pertenecientes a nueve familias lingüísticas peruanas, a saber: arahua, arahuaca, cahuapana, huitoto, jíbaro, pano, peba-yagua, tupí-guaraní y záparo, mostrando en cada caso texturas fónicas propias de cada idioma. En el Ecuador actual, fuera del quechua, el nombre se registra en las lenguas callapa, colorado, páez, cofán, shimigae y achuar; en Chile, lo registraba el atacameño, y lo consigna actualmente el mapuche; y en Bolivia, además del quechua, del aimara y del uro, lo consignan el mosetén, el yuracare, el tacana,

\footnotetext{
${ }^{2}$ Notemos, de paso, que la diferencia entre la notación con $<$ gu $>$ y con $<$ hu $>$ es puramente ortográfica, ya que, en ambos casos, se busca representar a la semiconsonante labiovelar /w/; la primera notación, vigente hasta poco más allá de la mitad del siglo XVI, es reemplazada en adelante por la segunda, tal como ya se puede ver en las notaciones de Blas Valera.

3 Tal como ocurría, y ocurre aun en los dialectos quechuas, en el caso del préstamo temprano waka, 'vacuno' en general (cf. piña waka 'toro bravo'), proveniente de vaca.

4 El mismo lexicógrafo trae, sin embargo, lo que vendría a ser una forma incorrecta <atahuallpavrco>, sin duda calcada del castellano, que en frases semejantes, a diferencia de lo que ocurre en quechua, exige el orden nombre-adjetivo (cf. Gonçález Holguín [1608] 1952: I, 36). Nótese, de paso, que empleamos los corchetes angulados " $<>$ " para encerrar entre ellos las formas del original; las barras "/ /" para toda notación fonológica; y los corchetes normales "[ ]" para la pronunciación aproximada de los términos estudiados.

5 Modernamente, los dialectos quechuas (exceptuando algunas variedades ecuatorianas) y aimaras solo registran, indistintamente para el gallo o la gallina, la designación de wallpa, es decir la forma abreviada, aunque no faltan designaciones locales para el ave macho, como es el caso de $k^{\prime} a n k a$, en el dialecto cuzqueño o en el aimara sureño (en alusión a la cresta rugosa del ave); o, en fin, la forma prestada gaallu, del castellano, presente en los dialectos del quechua central.

${ }^{6}$ La excepción es el mochica, lengua regional de la costa norte peruana, en la que prevaleció el nombre genérico adaptado de <ñaiñ $>$ 'ave' en lugar del préstamo de origen quechua.
} 
el chácobo, y lo registraban también el pacaguara y el apolista (cf. Nordenskiöld, 1922: 22-23). ${ }^{7}$

\section{El nombre del último inca.}

Como se habrá podido advertir, la variante completa del nombre del ave de corral coincide exactamente con el del último inca, que ha pasado al castellano bajo la forma de <Atahualpa>. En efecto, así lo confirman las fuentes lexicográficas primordiales del quechua, entre ellas el vocabulario del jesuita chachapoyano, que recoge <Atahuallpa> "Inca rey" (cf. Anónimo, [1586] 2014: I, 53), del mismo modo en que lo hace el cacereño, su compañero de orden: <atahuallpa inca> "el inca de Quito, dichoso en guerra" (cf. Gonçález Holguín, [1608] 1952: I, 36). Estas dos versiones, sin embargo, difieren de las recogidas en las documentaciones más tempranas del nombre, las que remontan a 1532, es decir la fecha en que se produce el asalto a Cajamarca por Pizarro y su hueste, y la consiguiente captura del inca. En efecto, por citar solo dos de las primeras de ellas, el nombre aparece registrado por los cronistas de la conquista Francisco de Jerez, secretario de Pizarro, y por Miguel de Estete; el primero lo consigna como <Atabaliba> (cf. Jerez [1534] 1968: 208) y el segundo en la forma de <Atabalica> (cf. Estete [1535] 1968: 367). ${ }^{8}$

Estas formas, más la primera que la segunda, recuerdan evidentemente las variantes, igualmente tempranas, consignadas por el lexicógrafo sevillano, como se vio en la sección anterior, es decir <atapallipa> <atapáliba>, aunque referidas solo a la gallina (Santo Tomás, [1560] 1994, II, fols. 61v y 111 , respectivamente).

Pues bien, dejando de lado formas como <Atabalica> o <Tavalipa>, que reflejan sin duda los primeros esfuerzos por reproducir en el papel los tanteos acústico-perceptivos de los españoles, interesa comentar las notaciones igualmente vacilantes del ilustre sevillano (ver, para una reflexión sobre el fenómeno, el estudio pionero de nuestro recordado maestro Luis Jaime Cisneros 1965). Y así, lo primero que se nota, contrastándolas con las versiones, más tardías y por consiguiente más estandarizadas, ofrecidas por Blas Valera y Gonçález Holguín, es que las del dominico presentan cinco sílabas allí donde las otras registran solo cuatro.

\footnotetext{
7 Fuera del préstamo castellano o portugués del nombre (prevaleciente en la región del Orinoco), la otra designación que el investigador sueco encuentra, en la parte oriental de Sudamérica, al sur de la cuenca amazónica, es de origen igualmente onomatopéyico, aunque esta vez imitando el cacareo de la gallina (cf. Nordenskiöld 1922, 13ss.).

8 En su nota algo desordenada sobre el tema, y supuestamente destinada a estudiar los problemas de notación del nombre del inca en mención, Seguí (2006) ofrece un listado de las distintas variantes con que aparece registrado el nombre en la documentación colonial más temprana, pero en la que brilla por su ausencia fray Domingo de Santo Tomás. Sin embargo, mucho más exhaustivo y fidedigno, un verdadero "abanico onomástico", según sus propias palabras, es el que presenta nuestro recordado maestro don Carlos Araníbar, en su edición reciente de Guaman Poma, cuyo volumen IV contiene el índice onomástico comentado de la obra (Araníbar [1615] 2015: 129-130).
} 
Dicho incremento silábico no podía ser ciertamente gratuito, y obedecía simple y llanamente a la presión ejercida por los hábitos de estructuración silábica del castellano entre sus hablantes, que prohibía, entre otras cosas, la aparición de una consonante palatal en sílaba trabada, en este caso de la lateral palatal $/ \mathrm{II} / .^{9}$

Una réplica más o menos próxima al estímulo requería, inevitablemente, una restructuración silábica, de manera que dicha consonante pasara a formar otra sílaba con apoyo de una vocal epentética, igualmente palatal, es decir /i/. ${ }^{10}$

En virtud de dicho soporte vocálico, se produce el incremento silábico mencionado, deviniendo en [a.ta.pa.lli.pa], o mejor aúnen <atapáliba>, es decir [a.ta.pá-li-ba], tal como se esmera en ponerle la tilde el ilustre lexicógrafo sevillano. ${ }^{11}$

Fuera de ello, restan por explicar, por un lado, la interpretación de /w/ como /p/ en la segunda sílaba, y la réplica sonorizada de la /p/ de la última, fenómenos ambos dictados por una falsa percepción del oído español, al principio acostumbrado a procesar secuencias de sonidos hasta entonces inusitadas a partir de sus propios hábitos articulatorios, que solo el tiempo y una mayor exposición a la lengua nativa irían afinando.

Ahora bien, que el nombre del ave (y el del último inca) es a todas luces un compuesto, nos lo recuerdan, en su diversa consignación, tanto Domingo de Santo Tomás como Blas Valera, al ofrecernos la variante <guallpa>, segmentada del componente inicial de su forma enteriza, y que es la forma que finalmente ha prevalecido por lo general en las lenguas nativas del ámbito serrano del área andina.

Por lo demás, que el nombre del inca era un sobrenombre compuesto, lo comprobamos al ver usados por separado sus componentes putativos, integrando otras formas composicionales, como antropónimos recurrentes dentro de la nobleza incaica.

Así, sin ir muy lejos, <Tupa Cusi Gualpa> era nada menos que el sobrenombre del hermano mayor de Atahualpa, es decir Huáscar; <Yacura

\footnotetext{
${ }^{9}$ Una manera de resolver dicho problema podría haber sido la depalatalización del segmento involucrado, tornándolo alveolar, es decir ///, como ha ocurrido en el topónimo <Pucallpa>, es decir /puka allpa/ 'Tierra colorada', que habitualmente se pronuncia [pukálpa]. Notemos, sin embargo, que en el mismo quechua se advierte cierta inestabilidad articulatoria de las líquidas cuando aparecen en posición de coda, y que nosotros atribuimos a sustrato puquina (como se ve en las variantes toponímicas <Collque $>\sim<$ Corque $>\sim<$ Colque $>$ 'Plata'). No extrañe, entonces, que el componente <guallpa> del nombre que estudiamos, y que figura como antropónimo y como designación dialectal del ave de corral, aparezca registrado también como $<$ Gualpa $>$ <Hualpa $>$.

${ }_{10}$ Así también, por ejemplo, en el caso del peruanismo <máchica> 'harina tostada', en lugar de /machka/, que es la forma más próxima a la etimología quechua.

11 Esto último, es decir la acentuación proparoxítona del nombre, es lo que trata de probar Óscar Coello (2007), mediante el escanciado dactílico que el poeta Diego de Silva y Guzmán le administra al nombre de <Ataválipa>, en su composición de arte mayor alusiva a la conquista del imperio incaico, escrita en 1538 en el Cuzco. A decir verdad, ya el lexicógrafo sevillano nos daba la pauta correcta de la acentuación del nombre, si bien no de manera sistemática (la falta podría achacarse a la impresión del texto en su conjunto) al colocarle la tilde respectiva, descartando la pronunciación paroxítona del mismo (es decir*[a.ta.ba.lí.pa]).
} 
Gualpa> era un capitán del último inca; y, en fin, <Tupa Gualpa $>,{ }^{12}$ el inca títere nombrado por Pizarro, era otro hijo de Huaina Cápac (cf. Betanzos [1551] 2015: II, XXVII, fol. 140v; II, III, fol. 101v; II, XXVII, fol. 140v, respectivamente). De otro lado, <Topa Atau> se llamaba otro vástago de Huaina Cápac, y venía a ser por tanto hermano de los soberanos enfrentados; y <Cori Atao> era también nombre de un capitán de Huáscar (cf. Betanzos, [1551] 2015: II, III, fol. 115; II, VII, fol. 107V, respectivamente). Incidentalmente, nótese que los datos ofrecidos en relación con el empleo independiente del primer elemento del compuesto, es decir <atao> <atau>, nos ayuda a "recuperar" la forma completa del mismo, que acaba en una semiconsonante labiovelar (es decir /w/), y que, en el compuesto $<$ Ataguallpa , se confunde con la consonante inicial de <guallpa ; de manera que, en verdad, el compuesto debe restituirse, provisionalmente según veremos, como /ataw-wallpa/.

\section{3. ¿Nombre del ave o del inca?}

Una vez establecida la relación entre el nombre del inca y el del ave de corral, conviene preguntarse sobre dicha homofonía, tal como lo hicieron en su tiempo, los historiadores del pasado y del presente. Al respecto, dos han sido las interpretaciones que se han formulado en relación con el problema suscitado por la homofonía de los nombres: por un lado, están quienes sostienen que el nombre del ave sería el originario a la par que el del inca tendría reminiscencias totémicas; por el otro, de signo contrario, la gallinácea habría tomado el nombre del soberano, que habría preexistido. Ambas posiciones, como se ve, enfrentan el problema de la motivación (= ex causa) del nombre: en un caso, por qué el inca recibe la misma designación que la de la gallina; y en el otro, por qué el ave toma el apelativo del inca. En última instancia, la primera asume que la cosa (= Sache), es decir el ave, existía antes de la palabra (= Wort); la segunda niega que ella existiera antes del nombre y que solo se usaba como antropónimo. En lo que sigue pasaremos a caracterizar cada una de tales posiciones.

\subsection{La precedencia del nombre común.}

Que sepamos, la postura a favor de esta hipótesis la formula por primera vez José de Acosta, el ilustre historiador jesuita de la colonia. En efecto, al ocuparse de las "aves que hay de acá [España], y cómo pasaron allá en Indias", refiere lo siguiente:

\footnotetext{
12 El nombre de este personaje aparece completamente distorsionado en algunas fuentes cronísticas a tal punto que su segundo componente no suele asociárselo con el elemento <guallpa>, tan deturpado como se muestra: <Toparpa>. Sin embargo, como ya lo sugerimos en la nota 9, la regla de las líquidas, en virtud de la cual estas alternan (y no solo en final de sílaba), nos permite no solo "restituir" su forma originaria como /tupa wallpa/ sino también sostener que debió existir la variante <guarpa> de <guallpa>, de manera que la distorsión del nombre no debe ser achacada únicamente, para usar una expresión cara al Inca Garcilaso, a "corruptela española". Sobre la interpretación del elemento <tupa>, de origen puquina, ver Cerrón-Palomino 2016: 16-17).
} 
"Pero dejando estas aues [como avestruces], que ellas por si se gobiernan, sin que los hombres cuiden de ellas, si no es por vía de caza; de aves domésticas me he maravillado de las gallinas, porque, en efecto, las había antes de ir españoles: y es claro indicio tener nombres de allá, que a la gallina llaman gualpa y al huevo ronto; y el mismo refrán que tenemos de llamar a un hombre gallina, para notalle de cobarde, ese propio usan los indios" (Acosta [1590] 1954: IV, XXXIII, 130).

Como puede verse, el autor no solo se limita a sostener que había gallinas en el Perú de los incas sino que, para fundamentar su aserto, recurre a un argumento al parecer contundente: la existencia previa del nombre quechua del ave, en este caso <gualpa>, además del de su producto, el huevo, designado como <ronto>, es decir /runtu/. Y no solo eso, porque nota también el historiador, a renglón seguido, que el conocido "refrán" (mote, diríamos modernamente) de tildar de gallina a los hombres pusilánimes y cobardes les era familiar a los indios en su lengua. ${ }^{13}$ Notemos de paso el mutismo del cronista respecto de la similitud del nombre del ave con el del último soberano incaico, lo cual no debió extrañarlo después de todo, desde el momento en que nominaciones semejantes eran también práctica común en el Viejo Mundo. De igual modo, se abstiene en asociar al inca con la acepción de cobarde que, según él, registraba el vocablo.

Pues bien, la hipótesis del jesuita historiador, rebatida por el Inca Garcilaso, y más tarde por el enciclopédico Cobo, según veremos más adelante, fue desarrollada principios del siglo XX nada menos que por el conocido etnógrafo sueco Nordenskiöld, en su interesante trabajo, citado previamente, de las designaciones empleadas por los indios sudamericanos para referir a los objetos culturales importados de Europa tras la conquista española. A diferencia del padre Acosta, sin embargo, si bien es de la idea de que el nombre de <guallpa> fue anterior al del inca, descarta la existencia previa del ave de corral en América, aunque sostiene su introducción en el subcontinente americano antes de la conquista incaica. A conclusión semejante llega tras revisar crónicas y relaciones de conquista tempranas del territorio sudamericano, proponiendo lo que él llama una ruta de comercio tribal que, partiendo de las costas brasileñas, habría posibilitado la difusión de la gallinácea traída por los primeros viajeros y exploradores portugueses y españoles, fuera del territorio amazónico, siguiendo el curso de los ríos, hasta llegar, por el noroeste y por el sudoeste, al antiguo país de los incas (Nordenskiöld, 1922: 18-26). ${ }^{14}$ En relación con el nombre del ave de corral,

\footnotetext{
${ }^{13}$ Sobre la vigencia del mote a comienzos del siglo XVII, oigamos lo que nos dice Sebastián de Cobarruvias, en la entrada sobre <GALLINA>, en su famoso Tesoro: "Al cobarde dezimos gallina por ser medrosa" (cf. Cobarruvias [1611] 1984: 622).

${ }^{14}$ Se le escapa, sin embargo, la referencia temprana ofrecida por el soldado cronista, según la cual Pizarro le habría encargado al orejón que lo visita cuando aquél llega por primera vez a las playas de Tumbes, en 1528, para que le entregara, en calidad de presentes al curaca del lugar (¿Chilimasa?), "una puerca y un verraco e quatro gallinas y un gallo" (Cieza de León [1551] 1987: XX, 54), agregando que cuando la autoridad los recibió "túvolo en más de lo que yo puedo encareçer, llegando todos a ver la puerca y el verraco y las gallinas, holgándose de oyr cantar el gallo" (Cieza de León [1551] 1987: XX, 55).
} 
que, a diferencia de lo que ocurrió con otros elementos culturales importados (como el del caballo, por ejemplo), tendría un origen quechua, sostiene que debió referir a una especie nativa que, al conocerse después la europea, pasó a designarla, por razones de similitud, operación designativa socorrida entre conquistadores y conquistados ante elementos culturales en principio extraños a ambos. ${ }^{15}$ Así, pues, para el investigador sueco, el ave de corral sería "el único elemento cultural del Nuevo Mundo que se difundió extensamente del área del imperio inca con un nombre quechua" (Nordenskiöld, 1922: 26). En suma, según el autor, habría sido Huaina Cápac, deslumbrado por la belleza del nuevo animal, el autor del sobrenombre de su hijo, quien habría pasado a conocerse como <Guallpa>. Por lo demás, Nordenskiöld parece descartar implícitamente, entre los antiguos peruanos, el disvalor metafórico del nombre al que hacía alusión el padre Acosta.

\subsection{Precedencia del antropónimo.}

La postura contraria a la del jesuita español y del etnógrafo sueco, nos la ofrece el Inca Garcilaso. Los argumentos manejados por el ilustre historiador, que obviamente buscan refutar los aducidos por el padre Acosta, se sustentan en la negación de estos, es decir: (a) en la inexistencia de las aves de corral en el antiguo Perú; y (b) en la constatación de que el registro de un nombre indígena para designar un elemento cultural determinado no es prueba de la existencia previa de dicha entidad. En efecto, discurriendo acerca de los animales introducidos al mundo andino por los españoles, observa lo siguiente:

"Tampoco havía gatos de los caseros antes de los españoles; ahora los hay, y los indios lo llaman micitu porque oyeron decir a los españoles "imiz, miz!" cuando los llamavan. Y tienen ya los indios introduzido en su lenguaje este nombre micitu, para decir gato. Digo esto porque no entiende el español que por darle los indios nombre diferente de gato, los tenían antes, como han querido imaginar de las gallinas, que porque los indios les llaman atahuallpa, piensan que las havía antes de la conquista, como lo dize un historiador, haziendo argumento que los indios tuvieron puestos nombres de su lenguaje a todas las cosas que tenían antes de los españoles, y que a la gallina llaman gualpa; luego, havíalas antes que los españoles passaran al Perú. El argumento parece que convence a quien no sabe la deducción del nombre gualpa, que no les llaman gualpa, sino atahuallpa" (Garcilaso de la Vega, Inca [1609] 1943: IX, XX, 259-260).

\footnotetext{
${ }^{15}$ En apoyo de su tesis, cita el autor a J. J. von Tschudi, el célebre viajero suizo que en sus relatos de exploración por la sierra central, menciona a una de tales especies, en los siguientes términos: "Hay una ave pequeña en la puna, del tamaño de un estornino. Su plumaje es muy hermoso, marrón con rayas negras en la espalda, gris con dos rayas negras en el cuello, y blanco en el pecho. Esta ave tiene la notable particularidad de emitir un sonido monótono durante la noche, al término de cada hora. Los indios la llaman Inga-huallpa, o gallo del Inca (ThinocorusIngae, Tsch.), y asocian muchas ideas supersticiosas con su grito regular de cada hora" (cf. Tschudi 1854: XI, 222). Todo parece indicar que se está aludiendo al pucu-pucu, nombre onomatopéyico, de manera que <inca huallpa>, o sea 'la gallina del inca' parece nombre impuesto tardíamente. Lo propio puede decirse de la /saĉawallpa/ 'gallina de monte', registrada por Gérald Taylor (1979: 193) para el quechua chachapoyano.
} 
Luego de refutar la tesis del registro del nombre nativo como prueba de la existencia de su referente, y tras anunciar que volvería sobre el asunto al ocuparse de las aves domésticas, retoma sus argumentos en contra, esta vez de manera más específica, aunque sin mencionar el nombre del historiador aludido, por el respeto y la veneración que le infundía. Dice, pues, el cronista cuzqueño:

"Será razón hagamos mención de las aves, aunque han sido pocas, que no se han llevado sino gallinas y palomas caseras [...]. De las gallinas escrive un autor que las havía en el Perú antes de su conquista, y házenle fuerça para certificarlo ciertos indicios que dize que hay para ello, como son que los indios, en su mismo lenguaje, llaman a la gallina gualpay al huevo ronto, y que hay entre los indios el mismo refrán que los españoles tienen, de llamar a un hombre gallina para notarle de covarde" (Garcilaso de la Vega, Inca [1609] 1943: IX, XXIII, 263).

Y a renglón seguido, rebatirá los indicios aducidos por el historiador mencionado, buscando satisfacer al lector, "con la propriedad del hecho", en los siguientes términos:

"Dexando el nombre gualpa para el fin del cuento, y tomando el nombre ronto, que se ha de escrevir runtu [...], dezimos que es nombre común; significa huevo; no en particular de gallina, sino en general de cualquier ave brava o doméstica, y los indios en su lenguaje, cuando quieren decir de qué ave es el huevo, nombran juntamente el ave y el huevo, también como en español, que dize huevo de gallina, de perdiz o paloma, etc; y esto baste para deshacer el indicio del nombre runtu" (Garcilaso de la Vega, Inca [1609] 1943: 263).

Queda claro entonces, para el Inca historiador, que el argumento de la existencia del nombre quechua del gallo/ gallina no es razón para sostener que el ave no haya sido traída por los españoles. De otro lado, en cuanto al nombre mismo, que Acosta registra como <gualpa>, el Inca nos dirá, siguiendo su vieja costumbre de enmendarles la plana a los españoles en materia de pronunciación quechua, que "está corrupto en las letras y sincopado o cercenado en las sílabas, que han de decir atahuallpa, y no es nombre de gallina, sino del postrer Inca que hubo" (Garcilaso de la Vega, Inca [1609] 1943: 264). ${ }^{16}$ Fuera de los aspectos de pronunciación, interesa destacar aquí

\footnotetext{
${ }^{16} \mathrm{Si}$ bien hay que darle la razón al Inca en cuanto a la rectificación de la pronunciación de $<$ ronto> por < runtu>, en la cita del padre Acosta, en el caso de <gualpa > no podemos dejar de recordar que el propio historiador mestizo empleaba dicha forma, es decir <Gualpa $>$, al nombrar, en la dedicatoria de su traducción de los Diálogos de Amor, a su tío abuelo por vía materna, <GualpaTopac>. Como lo señalamos en otro lugar, dicha práctica es abandonada por el Inca cuando llega a sus manos el Arte y vocabulario (1586) preparado por el Tercer Concilio Limense, en el que se normaliza la escritura del quechua sobre la base de la variante cuzqueña, proceso en el cual es decisiva la participación de su mentor Blas Valera (CerrónPalomino 2013b: III, § 3). En adelante, el Inca escribirá el mismo nombre como $<$ HuallpaTupac $>$.
} 
el carácter normativo que subyace a su razonamiento, y que recoge las enseñanzas de su mentor Blas Valera: el nombre, originariamente del inca, y por extensión del ave, es la forma compuesta y no la abreviada, que sin embargo se empleaba también, según testimonio del primer lexicógrafo quechua y del propio Acosta. Ya se dijo, sin embargo, que la versión que se impondrá finalmente en el mundo andino, aunque no en el amazónico, será la recusada por el Inca, es decir la versión "cercenada", o sea /wallpa/.

Ahora bien, en cuanto al otro indicio aportado por el historiador Acosta, consistente en la existencia entre los indios del "refrán" según el cual el cobarde era motejado de 'gallina', nuestro cronista considera ser, igualmente, algo tomado ("hurtado", según expresión suya) de los españoles. Oigamos, en efecto, la digresión del Inca sobre el asunto:

"El refrán de llamar a un hombre gallina, por motejarle de covarde, es que los indios lo han tomado de los españoles, por la ordinaria familiaridad y conversación que con ellos tienen; y también por remedarles en el lenguaje, como acaesce de ordinario a los españoles que passando a Italia, Francia, Flandes y Alemañia, bueltos a su tierra quieren luego entremeter en su lenguaje castellano las palabras o refranes que de los extranjeros traen aprendidos; y assí lo han hecho los indios, porque los Incas, para decir covarde, tienen un refrán más apropiado que el de los españoles; dizen huarmi, que quiere dezir mujer, y lo dizen por vía de refrán; que para decir covarde, en propria significación de su lenguaje, dicen çampa, y para decir pusilánimo y flaco de coraçón dicen Ilanclla. ${ }^{17}$

De manera que el refrán gallina para decir covarde es hurtado del lenguaje español, que en el de los indios no lo hay, y yo como indio doy fe desto" (Garcilaso de la Vega, Inca [1609] 1943: 263-264).

De este modo, por un lado, explicando la supuesta acepción metafórica de 'cobarde' para <atahuallpa> como un préstamo semántico tomado de los españoles; y, por el otro, llamando la atención sobre el registro en lengua nativa de términos usuales que expresan dicho concepto, y de rebote sobre el carácter peregrino de la acepción referida, acaba el Inca por desbaratar todos los "indicios" que a favor de la existencia previa de las aves de corral en el imperio incaico había presentado el historiador Acosta. ${ }^{18}$

Pues bien, la persona que en nuestros tiempos se pronuncia por una interpretación del asunto en términos que coinciden parcialmente con los del Inca, aunque con proyecciones etnohistóricas que van más allá de lo discutido hasta aquí, es la investigadora norteamericana Linda Seligmann, en su estudio

\footnotetext{
17 Se trata de una errata que sigue arrastrándose desde la princeps editio de la obra, pues el mismo autor nos da, en otro lugar, la pronunciación y el silabeo correctos de la voz: <llac-lla>, es decir /llaqlla/ (Garcilaso de la Vega, Inca [1609] 1943: VII, IV, 96).

18 Cierto improvisado autor pretende refutar al Inca sosteniendo la misma tesis del padre Acosta, aunque sin base alguna y con desinformación total de las fuentes, pero yendo más allá, al afirmar muy suelto de huesos, sobre la base de una alucinada imaginación, que el último inca habría tenido otro nombre, y que el de Atahuallpa 'gallina' (cuya etimología sería *wayranallpa en vista de que el ave escarba y arroja la tierra con las alas!), con el valor metafórico de 'cobarde', se lo habrían impuesto los españoles al verlo llorar desconsoladamente tras el anuncio de su muerte inminente (Latorre 2012: 46-47).
} 
histórico y etnográfico acerca del concepto quechua del vocablo wallpa (Seligmann 1987). ${ }^{19}$

En efecto, tras evaluar las fuentes documentales coloniales tanto cronísticas como lexicográficas e incorporar datos etnográficos relacionados con el tema obtenidos en sus trabajos de campo conducidos en algunas comunidades cuzqueñas, la estudiosa llega a la conclusión de que habrían sido los hablantes quechuas quienes echaron mano del antropónimo del inca Atahualpa para designar también, de manera sugestiva y pintoresca, al ave de corral traída por los españoles (Seligmann 1987: 149-150). A diferencia de lo señalado por el Inca historiador, sin embargo, ella no descarta que el término hubiera adquirido al mismo tiempo la acepción de 'cobarde' en el contexto del contacto con los españoles. De este modo, el nombre atawallpa, o su versión recortada de wallpa, habría tenido doble valor: positivo y negativo, trasuntando la reputación igualmente ambigua de que gozaría el postrer inca del imperio.

\section{La motivación del nombre.}

Corresponde ahora ver la motivación del nombre, ya sea como antropónimo del inca o como designación traslaticia del ave de corral. Al respecto, según se recordará, el historiador Acosta no dice nada sobre el asunto, y no se hace problemas con la coincidencia entre el nombre del ave y el del inca, seguramente por el hecho de que, como dijimos, no le resultaba nada extraño que las personas llevasen nombres de animales. El etnógrafo Nordenskiöld, en cambio, sugiere que habría sido Huaina Cápac quien le habría puesto el nombre del gallo a su futuro heredero y diligente compañero de sus conquistas ecuatorianas, impresionado por la cresta altanera y el vistoso plumaje de este. Sobra señalar que ambos autores postulan la precedencia del nombre común y de su referente al antropónimo privativo de la casta imperial, ya sea como animal nativo o como importado en tiempos previos a la conquista. Quienes, por el contrario, se oponen a ello, y postulan la preexistencia del sobrenombre al nombre del ave, ofrecen razones que explicarían la causación de la transposición designativa. Y así, mientras que los historiadores mestizos Blas Valera y Garcilaso, y en este caso también el cronista indio Pachacuti Yamqui Salcamayhua, aducen una motivación onomatopéyica, la etno-historiadora Seligmann sugiere un móvil de naturaleza mítico-histórica. Seguidamente veremos ambos tipos de raciocinio etimológico.

\footnotetext{
${ }^{19}$ Lo que en verdad interesa a la investigadora no es tanto enfrascarse en la discusión sobre la posible motivación onomatopéyica del nombre sino, más bien, lo que habría significado el canto del gallo para los indios a raíz de la captura y muerte del inca Atahualpa. Según su interpretación, el canto del ave indicaría una suerte de pachacutiy, es decir la ruptura del orden establecido, el trastorno del mundo y el comienzo de una nueva etapa en su devenir; y así, la investigadora cree encontrar en las comunidades cuzqueñas que estudia esta misma asociación entre el canto del gallo y ciertos acontecimientos que subvierten el orden en la vida de los pueblos. La palabra wallpa, concluye, "devino en marcador de un pachakuti, un cataclismo del mundo nativo" (Seligmann 1987: 156).
} 


\subsection{Origen onomatopéyico.}

Considerado por el Inca Garcilaso como un "cuento gracioso", esta interpretación parecen haberla obtenido tanto el mestizo chachapoyano como el cuzqueño, al parecer por separado y en distintos lugares. Oigamos primeramente lo que nos dice al respecto Blas Valera, citado por el Inca, en el mismo capítulo en el que trata sobre el tema, en verdad en apoyo de su propia explicación. Refiere, pues, el mestizo chachapoyano

"que cuando su muerte [la de Atahualpa] fue divulgada entre sus indios, porque el nombre de tan gran varón no viniesse en olvido, tomaron por remedio y consuelo dezir, cuando cantavan los gallos que los españoles llevaron consigo, que aquellas aves lloravan la muerte de Atahuallpa, y que para su memoria nombravan su nombre en su canto, por lo cual llamaron al gallo y a su canto atahuallpa; y de tal manera ha sido recebido este nombre en todas naciones y lenguas de los indios, que no solamente ellos, mas también los españoles y los predicadores, usan siempre dél" (Garcilaso de la Vega, Inca. [1609] 1943: 265).

Según esta interpretación, el canto del gallo estaría remedando, en la percepción acústica e imaginativa de los indios, el nombre del inca, y de esta manera, la arbitrariedad inicial del signo se vería conectada a un estímulo físico novedoso al oído de los naturales. La misma interpretación, sin dejar de considerarla como una "fábula", nos la proporciona el Inca, esta vez con el ingrediente de su testimonio personal, de manera más detallada y "donosa", para emplear un adjetivo caro a él. Conviene, pues, que lo citemos in extenso.

"A esta falsa creencia que tuvieron de los españoles [de que el Sol les había enviado a los españoles para que castigasen al tirano Atahualpa], se añadió otra burlería mayor, y fue que como los españoles llevaron gallos y gallinas que de las cosas de España fué la primera que entró en el Perú, y como oyeron cantar los gallos dixeron los indios que aquellas aves, para perpetua infamia del tirano y abominación de su nombre, lo pronunciavan en su canto diciendo "iAtahuallpa!", y lo pronunciaban ellos contrahaziendo el canto del gallo.

$Y$ como los indios contassen a sus hijos estas ficciones, como hizieron todas las que tuvieron, para conservarlas en su tradición, los indios muchachos de aquella edad, en oyendo cantar un gallo, respondían cantando el mismo tono y decían "iAtahuallpa!". Confiesso verdad que muchos condiscípulos míos, y yo con ellos, hijos de españoles y de indias, lo cantamos en nuestra niñez por las calles, juntamente con los indiezuelos.

Y para que se entienda mejor cuál era nuestro canto, se pueden imaginar cuatro figuras o puntos de cantos de órgano en dos compases, por los cuales se cantava la letra atahuallpa; que quien las oyere verá que se recuerda con ellos el canto ordinario del gallo; y son dos semínimas y una mínima y un semibreve, todas cuatro figuras en un signo. Y no sólo nombraban en el canto al tirano, mas también a los capitanes más 
principales, como tuviessen cuatro sílabas en el nombre, como Challcuchima, Quilliscacha y Rumiñaui, que quiere dezir ojo de piedra, porque tuvo un berrueco de nuve en un ojo. Esta fue la imposición del nombre atahuallpa que los indios pusieron a los gallos y gallinas de España" (Garcilaso de la Vega, Inca. [1609] 1943: 264-265).

Nos enteramos ahora que para el Inca y sus camaradas mestizos e indios el canto del gallo no solo remedaba el nombre del último soberano sino también el de sus capitanes famosos (deja de lado el cronista el nombre de $<$ Quizquiz> por ser bisilábico) en la medida en que compartían una métrica silábica similar. Esto último, sin embargo, huele a ingrediente ampliatorio y posterior. Que el canto evocaba sobre todo el nombre del postrer soberano inca, lo confirma el cronista de Canas y Canchis, en los siguientes términos:

"Al fin, al Atao Guallpa echa presso [Pizarro] en la cárcel, y allí canta el gallo, y Atao Guallpa Ynga dize: "hasta los abes saben mi nombre de Atao Guallpa" (cf. Pachacuti [1613] 1993: fol. 43r).

Los tres cronistas coinciden, como se ve, en el origen onomatopéyico del nombre del ave de corral. Sin embargo, dejando de lado el testimonio "neutral" de Pachacuti, los de Blas Valera y de Garcilaso discrepan en cuanto al mensaje de profundas connotaciones políticas que dicen que conllevaba el canto: por un lado, según la versión del primero, los gallos "lloravan la muerte" del soberano y "para su memoria nombraban su nombre"; mientras que para el segundo, el canto lo evocaba "para perpetua infamia del tirano y abominación de su nombre". Posiciones encontradas, como se ve, y que responden, sobre todo en el caso de Garcilaso, a su conocida ojeriza a los familiares y partidarios del inca Atahualpa y su identificación con la descendencia del linaje de Huáscar (Rostworowski [1988] 2014: 150 ss.). De hecho, el propio cronista busca resolver, tratando de calmar las aguas, su discrepancia con su mentor chachapoyano respecto del mensaje del canto del gallo, relativizando el hecho y concluyendo salomónicamente que, a fin de cuentas, "cada uno dize de la feria como le va en ella". Refiere, pues, el Inca que su mentor Valera

"recibió [la relación citada en párrafos anteriores] en el reino de Quitu de los mismos vassallos de Atahuallpa, que, como aficionados de su Rey natural, dixeron que por su honra y fama le nombraban los gallos en su canto, y yo la recebí en el Cozco, donde hizo grandes crueldades y tiranías; y los que las padecieron, como lastimados y ofendidos, dezían que para eterna infamia y abominación de su nombre lo pronunciaban los gallos cantando" (Garcilaso de la Vega, Inca. [1609] 1943: IX, XXIII, 265).

Pues bien, como alabanza o vituperio, creemos que no es forzado sostener que el canto del gallo, que tanto había impactado a los tumbesinos cuando lo escucharon cantar la primera vez (ver la nota 14 con la cita de Cieza), fuera interpretado, en la imaginación de los indios que presenciaban la ejecución del 
inca, como un remedo solidario, a la vez estentóreo y lastimero, de su nombre, según nos lo insinúa la cita del cronista indio.

\subsection{Motivación mito-histórica.}

El sentimiento dividido visto en relación con la personalidad del inca Atahualpa es retomado por Linda Seligmann en su discusión sobre la motivación del nombre del ave, pero esta vez buscando introducir en el debate la acepción de 'cobarde' que, según la investigadora, conllevaba también la palabra, como lo había señalado el historiador Acosta, aunque referida exclusivamente a la gallina, y como concepto de origen europeo. Para ello, se vale de las versiones recogidas por los cronistas, que tienen que ver con los atributos que habría tenido el inca Atahualpa, según los bandos de informantes en disputa, bien como el hijo victorioso y legítimo heredero de Huaina Cápac, o como el hermano afeminado y traidor de Huáscar, usurpador del trono. ${ }^{20}$

Así, pues, el soberano quiteño habría sido visto al mismo tiempo como guerrero victorioso y como cobarde afeminado, de manera que frente al gallo y a la gallina, traídos por los españoles, la metáfora de estos respecto del ave venía a calzar como anillo al dedo: el 'gallo' simbolizaba "gallardía, gentileza, bizarría" (Covarrubias [1611] 1984: 625), en contraste con la 'gallina', equivalente de "medroso"; así también, en el imaginario europeo, mientras que el canto estentóreo del gallo suena a grito "victorioso", el cacareo de la gallina, más aún cuando está incubando, evoca el de la derrota y la resignación. Estas connotaciones, adherentes al antropónimo del inca, habrían permeado también el nombre del ave (cf. Seligmann, 1987: 149-150).

Pues bien, ¿qué habría de cierto en dicha interpretación? Al respecto, debemos manifestar, siguiendo al Inca Garcilaso, que tales connotaciones fueron y son ajenas a la mentalidad andina, como lo prueban no solo las fuentes lexicográficas coloniales sino también los dialectos modernos del quechua y del aimara, en las que no aparecen registradas, brillando por su ausencia. Por lo demás, traer a cuento la visión faccionalista de la narración mito-histórica referida a los protagonistas de los últimos años del imperio, en auxilio de la explicación acerca de la motivación supuestamente aleatoria del nombre, nos parece un anacronismo interpretativo.

\section{Etimología popular reivindicada.}

\footnotetext{
${ }^{20}$ La atribución de Atahualpa como afeminado fue seguramente propiciada y difundida por el propio Huáscar y los miembros de su linaje, según se puede inferir a partir del pasaje del cronista lucaneño, quien refiere que este le habría retribuido a su hermano, en respuesta a unos presentes de reconocimiento y vasallaje que aquél le había mandado previamente, con "bestidos de mugeres y ollas y chamillcos y cantarillos todo de oro y acxo, lliclla, uincha, topo, pines, lirpo, naccha, chunbes, oxotas, todo de muger" (subrayado y comas introducidos; Huaman Poma de Ayala [1615] 2015: 117, 86). Sin ello, conviene recordar también el incidente relatado por Sarmiento, según el cual Huaina Cápac habría llevado consigo en la conquista de Pasto al joven Atahualpa, como para "probarlo", expedición de la cual habría huido el mozo al primer choque con los naturales, siendo increpado "malamente de palabra" por su padre (Sarmiento de Gamboa [1572] 1960: [63], 265).
} 
Evaluadas ambas interpretaciones que buscan ofrecernos la motivación del nombre del ave, como producto de una onomatopeya en la tesis del Inca, o como una transmutación semántica de un nombre que ya conllevaba las connotaciones atribuidas por los españoles al ave de corral, en la propuesta de Seligmann, debemos anunciar que nos inclinamos por la primera, procediendo a exponer nuestras razones para ello.

Pues bien, dejando de lado la tesis de la inexistencia de aves de corral en el mundo americano poco antes de la conquista española, y que nadie discute en la actualidad (la animalia representada en la cerámica y en los tejidos prehispánicos así lo confirman), no hay duda de que su designación con nombre nativo, lejos de ser originaria, no solo es derivada sino también tardía.

En tal sentido, las fuentes lexicográficas coloniales son unánimes al registrar la forma enteriza del nombre, es decir <Atahuallpa>, para designar al gallo y a la gallina, como lo prueba su difusión etimológicamente indiscutible entre los pueblos pertenecientes no solo al antiguo imperio de los incas, como observaba el historiador Cobo a mediados del siglo XVII (Cobo [1653] 1956: X, XI, 390), sino también entre los de sus comarcas fronterizas de la Amazonía, aunque la variante que finalmente se impondrá en el área andina será su forma abreviada, o sea <huallpa $>$.

De otro lado, sin contradecirnos con lo que siempre hemos venido sosteniendo y comprobando en nuestros estudios sobre onomástica andina (por ejemplo, Cerrón-Palomino 2008), pero sobre todo al estudiar las etimologías del Inca Garcilaso (Cerrón-Palomino 2013b: caps. IV-V, VII), ocurre que en esta oportunidad estamos llanos a suscribir el móvil de la designación del gallo/ gallina en quechua como resultado de la onomatopeya del canto del ave, en razón de la plausibilidad icónica de la réplica del modelo.

Es la misma posición adoptada por el cronista Cobo, al suscribir toda la argumentación del Inca historiador, al mismo tiempo que desautoriza implícitamente, por postizas, las connotaciones de gallardía y sumisión que se le pretendía adosar al nombre (Cobo [1653] 1956: 390). ${ }^{21}$

De aceptarse la hipótesis propuesta, aquí tendríamos un típico caso de etimología popular, que, no obstante ser considerada por el propio Inca como una "burlería" o un "cuento gracioso" en boca de los indios, cuenta con todas las evidencias de peso en su favor. En el ámbito de la disciplina etimológica, sin embargo, no parece haber cabida para la llamada etimología popular, practicada libre de toda coerción de índole lingüística y filológica, y como resultado de la irrefrenable tendencia a la asociación arbitraria entre unas formas y otras a la que es propenso el hablante común y corriente de una

\footnotetext{
${ }^{21}$ Notemos de paso, sin embargo, que el jesuita registra el nombre como <Atauhualpa $>$ y no $<$ Atahualpa>, como ha pasado hasta nosotros. El parcial <Atau> estaría ciertamente más cercano a la etimología, como lo hemos adelantado en $\S 2$, y como volveremos sobre el punto en la sección siguiente. El editor de Cobo, en este caso Francisco Mateos, comenta la etimología del nombre presentada por el cronista observando que el origen propuesto sería "tan pueril como inexacto", ya que, según su parecer, "una cosa es Atauhuallpa y otra Atahuallpa o Huallpa, polla joven o adulta, probablemente de alguna de las especies peruanas del género Penelope" (cf. Cobo [1653] 1956: X, XI, nota 5, 390). El argumento no tiene sustento alguno, y la diferencia que él cree ver entre $<$ Atahualpa $>$ y $<$ Atauhualpa $>$ es solo de notación.
} 
lengua. ${ }^{22}$ Por lo general cuestionada en todo trabajo serio en materia de averiguación etimológica, los etimologistas científicos no siempre están llanos a concederle un lugar dentro de su campo de reflexión, o a lo sumo lo hacen subsumiéndola dentro de los procesos analógicos y asociativos generales que operan en toda lengua (Zamboni 1988: 146-161; Brucker 1988: 57-60, 6266). En el presente caso, sin embargo, habrá que darle la razón alguna vez a la etimología popular y espontánea que da cuenta y razón de la motivación y generalización del nombre del inca para designar el gallo y la gallina en el área andina, concebida ésta en su abarque más amplio. Se trata, con todo, de una etimología secundaria, y no primaria, como pasaremos a argumentar en la sección siguiente.

\section{Origen puquina del nombre: etimología primaria.}

Hasta aquí, quienes se han ocupado de la etimología del nombre tanto del inca como del ave han asumido que estamos ante una designación de cuño formalmente quechua. Ello no debe extrañar desde el momento en que, como ha sido y es aún práctica entre los estudiosos del área andina, se da por descontado el origen cuzqueño de esta lengua, y por consiguiente de los nombres propios e institucionales del incario, lo que a su vez responde a la trasnochada visión cuzco-céntrica del quechua (y altiplánica del aimara, agregaríamos). Conforme lo hemos venido probando en los últimos años, sin embargo, los estudios etimológicos atingentes a tales dominios de la onomástica andina (Cerrón-Palomino 2013a), no dejan duda alguna de la fuerte procedencia puquina de esta, como era de esperarse, habiendo sido la colla-puquina la lengua primordial de los incas legendarios. No sorprende entonces que el nombre que nos ocupa, y sus reflejos modernos, remonten precisamente a dicho idioma. Nuestro paso siguiente estará destinado a dicha probanza.

Para ello, es conveniente que retomemos la forma a la que habíamos llegado en 2, postulando el compuesto /atawwallpa/ como una primera aproximación a la estructura subyacente del nombre del inca. A partir de esta construcción típica de frase nominal quechua, con modificador que precede a su núcleo, podemos identificar el adjetivo /ataw/ precediendo al nombre nuclear /wallpa/. Ambos componentes aparecen registrados en los tratados lexicográficos del quechua, en tanto que en los del aimara solo se da el segundo. De la manera en que fueron lematizados, el primero lo hace como forma libre, es decir con autonomía léxica, a la par que el segundo se muestra en forma ligada, o sea desprovisto de independencia. Se trata de un buen indicio para sostener que en el primer caso estaríamos ante un adjetivo y en el segundo frente a un verbo.

\footnotetext{
22 Se ha cuestionado el empleo del calificativo "popular" al caracterizar el tipo de etimología en cuestión, aduciéndose que resulta despectivo, sobre todo al oponérsela a la etimología erudita o "sabia", no necesariamente científica.

Para salvar el impasse etimológico nos parece que sería mejor hablar de una etimología ingenua frente a otra consciente o deliberada, practicada habitualmente por los aficionados, por lo general al margen de todo rigor exigido por la disciplina.
} 
Dicho esto del significante, toca averiguar ahora la cuestión más delicada del significado. Asunto es este que, menos mal, puede ser extraído, al menos parcialmente, de las glosas que al respecto nos ofrecen los documentos coloniales. En este punto, sin embargo, será bueno recordar las advertencias metodológicas relacionadas con las consideraciones hermenéuticas a tomarse en cuenta al momento de interpretar las glosas proporcionadas por los lexicógrafos, que en casos como los que veremos se resienten de una manipulación deliberada del significado de algunos términos al ponerlos al servicio de su tarea evangelizadora.

Pues bien, uno de tales términos es, precisamente, el del verbo /wallpa-/, cuya glosa principal, proporcionada por Blas Valera y secundada por Gonçález Holguín, vendría a ser "formar Dios y hazer, o criar" (Gonçález Holguín [1608] 1952: I, 174), de manera que el participio <huallpa-k>, o sea /wallpa-q/, o <huallpa-pu> según el mismo lexicógrafo, sería el "atributo que se da a Dios; hacedor, formador, \&c." (Anónimo (Blas Valera) [1586] 2014: I, 103). ${ }^{23}$

Tales acepciones son, sin duda alguna, resemantizaciones "abusivas e inexactas" del significado originario del verbo y de sus derivados, como señalan Duviols (1977) e Itier (1993: IV), las mismas que, sopesadas a la luz de otras glosas menos agustinianas, y que afortunadamente emergen de los listados ofrecidos a renglón seguido por los citados misioneros, pueden ayudarnos a descubrir, en parte al menos, los alcances sémicos prístinos de la raíz verbal en discusión. Según esto, el radical /wallpa-/ habría tenido las acepciones de 'formar', 'diseñar', 'disponer', y hasta 'juzgar' (pero no la de 'crear'); y sus derivados nominales tendrían igualmente un significado menos celestial y más terrenal, o si se quiere artesanal, que expresaría la agencia o actividad propia de un héroe cultural andino y no la de una divinidad judeocristiana impuesta (Itier 1993: 169).

De hecho, la forma verbal nominalizada, y con ponderación suma, o sea <gualpa-i-huana>, y que Gonçález Holguín traduce como "el diligente trabajador o fervoroso y animoso" (Gonçález Holguín: I, 174: huallpa-y huana>) aparece como un epíteto para aludir a Viracocha, en la conocida "oración por ynga", recogida de sus informantes nativos por el célebre quechuista Cristóbal de Molina (Molina 1573: fol. 17r).

Por lo demás, referidos a acciones humanas y no divinas, encontramos ejemplos como <huallpa-ri-k>, el que "haze bien algo de manos"; o <huallpari-ku-> "armarse para las guerras galanamente" o "adornarse y vestirse muy hermosamente" (Gonçález Holguín [1608] 1952: I, 174). Acepción parecida es la que recoge para el aimara su compañero de orden, registrando para la entrada <huallpa-> "apercebir lo que es menester para alguna obra, edificio, viaje, guerra \&c.", como en <yapuhuallpa-tha> "apercíbome para la chacara, o tengo ya apercebido para ello" (Bertonio [1612] 1984: II, 145).

Sin embargo, a diferencia de lo que ocurría en quechua, en la lengua altiplánica el radical podía funcionar también como sustantivo, a estar por ejemplos como los de <huallpa-ni> "el capitán, o el que tiene cargo el aportar para el banquete, y para las otras cosas susodichas" o el de <mankahuallpa-

\footnotetext{
${ }^{23}$ Con el fin de facilitar la exposición, de aquí en adelante las expresiones nativas citadas serán presentadas en forma analizada, es decir identificando y separando con un guion los elementos morfológicos que las subyacen.
} 
ni> "maestresala" (Bertonio [1612] 1984: II, 145), en los que la terminación ni equivale al derivativo -yuq en quechua, sufijo este incompatible con su equivalente quechua (no se da aquí $*<$ huallpa-yoc $>$ ); del mismo modo, si bien en esta lengua se registra el deverbativo <huallpa-k>, el aimara no registra un equivalente $*<$ wallpi-ri $>{ }^{24}$

En cuanto al significado del elemento modificador del compuesto, es decir /ataw/, no parece haber problemas de interpretación, pues las fuentes indican que equivalía a <cussi> (o sea /kuşi/) "dicha o ventura o contento", del quechua general, y a <çami> (es decir /sami/) "dicha o ventura", del quechua cuzqueño (cf. Anónimo, op. cit: I, 73.76); e incluso, en esta misma variedad, se registraba <qquillpo> (o sea /qillpu/) "la ventura en cosas grandes de mucha estima" (Gonçález Holguín [1608] 1952: I, 77). ${ }^{25}$

Sin embargo, un significado más primitivo, es decir libre de contaminaciones misioneras, nos lo estaría proporcionando el suplemento 2 del célebre manuscrito de Huarochirí, que consigna la voz <ata> (Anónimo [1608] 1987: 513 , passim). ${ }^{26}$

Concretamente, <ata> viene a ser el enviado por la divinidad, en este caso el rayo, y señalado por una rareza en la configuración de la distribución del cabello, una <parca>, voz que burla atención del traductor, y que sin embargo se trata simplemente de una variante de /pallqa/ 'bifurcación'.

En el texto, el <ata> es el enviado de los dioses locales Pariacaca y Tutayquiri, y cuya ceremonia del corte de pelo se describe. No hay duda, entonces, de que <ata> viene a ser el 'tocado o señalado por la divinidad', en una palabra el 'agraciado' o el 'iluminado'; $y$, en tal sentido, es el mismo radical nominal que encontramos en <ataw/, solo que en esta oportunidad, gracias al dato proporcionado por el anónimo de Huarochirí, caemos en la cuenta de que esta forma no era irreductible, como pensábamos, sino pasible de una segmentación en la que podemos aislar el último segmento, es decir /w/, que no puede ser sino un sufijo.

¿Qué morfema gramatical sería este? Descartado el quechua por no tener un candidato, creemos que el sufijo ubicativo-existencial aimara, que tiene la forma de /-wi/, puede auxiliarnos en el problema de su identificación. Y así, en base a ello, postulamos el derivado aimara */ata-wi/ 'el que tiene dicha', que

\footnotetext{
${ }^{24}$ A decir verdad, sin embargo, también en el quechua encontramos ejemplos en los que <huallpa> funciona como nombre: así, en <Huallpa-n> "el entremetido intérprete de otro", o en la pregunta <pi-p huallpa-n-mi canqui> "¿cuyo intérprete eres?" (Gonçález Holguín [1608] 1952: I, 174).

25 De estos dos últimos sinónimos, el segundo debía mostrarse algo oscuro ya, de manera que en una expresión como <cussiqquillpo runa> "el dichossíssimo con dicha grande" no resultaba redundante, aunque debemos agregar que la aclaración que el cacereño le añade en su definición, advirtiendo que la expresión se tomaba "por los bienaventurados, o los que alcançan gracia, o virtudes" (Gonçález Holguín [1608] 1952: 2I, 309), ya tiene un tufo catequético.

26 Gérald Taylor no alcanza a traducir esta palabra, aun cuando el anónimo autor del texto sugiere que se trata de un equivalente de $<$ ylla $>$, o sea /illa/ (<yllañispaca ata $>$ ), definido por Blas Valera como "ditado [título de dignidad] de incas señores" (Anónimo [1608] 1987: I, 114).
} 
luego se quechuiza en /ata-w/, siguiendo una antigua regla de apócope consonántica que afectaba a la lengua. ${ }^{27}$

Ahora bien, volviendo al compuesto <ata-w wallpa>, sobra señalar que la frase resulta un tanto anómala en quechua, desde el momento en que el verbo /wallpa-/, para entrar en una construcción como la estudiada, debía manifestarse en forma nominalizada; y, sin embargo, el compuesto llegó a nosotros tal como aparece registrado, es decir <ata-u-huallpa $>$. Ninguna de las variantes del nombre reviste una forma como $*<$ ata-o-huallpa-c>, o sea */ata-w wallpa-q/, o algo por el estilo, que vendría a ser la correcta, interpretable llanamente como 'el diligente o animoso feliz'. ¿Cómo explicar entonces el glosado "dichoso en guerra", que ofrece Gonçález Holguín para su entrada de <Atahuallpa inca> (Gonçález Holguín [1608] 1952: I, 36)? En verdad, todo parece indicar que estaríamos ante una expresión ya lexicalizada, con pérdida de la marca agentiva de */wallpa-q/, como resultado de la caída de la consonante postvelar / $q /$ en final de dicción, fenómeno que, como se sabe, caracterizaba a la "lengua general", llamada también chinchaisuya, y de la que nos hablan los primeros cronistas, según ha sido señalado por los estudiosos de esta variedad (por ejemplo, Cerrón-Palomino 2013a: 332336). ${ }^{28}$

Pues bien, a estas alturas del análisis propuesto, no parece haber duda de que las raíces */ata/ y */wallpa-/ sean advenedizas en el quechua y en el aimara. Su registro limitado a las variantes coloniales de estas lenguas, su empleo en fórmulas y expresiones mayormente lexicalizadas, pero sobre todo como recurso antroponímico, y su aprovechamiento posterior por parte de los misioneros para "intelectualizar" las lenguas al servicio de sus fines proselitistas, abonan el carácter foráneo de tales formas léxicas, como posiblemente ocurre también con <çami> y <qquillpo>, propias del léxico litúrgico adaptadas. ${ }^{29}$ Siendo así, y en el estado de nuestros conocimientos, no cabe otra alternativa que postular un origen puquina para los elementos constitutivos del nombre compuesto */ata-w wallpa/, y que con seguridad formaban parte del llamado "lenguaje particular" de los incas, pasados por el filtro aimara previamente y por el quechua después.

Admitamos, sin embargo, que probar de manera terminante dicha etimología, en forma y significado, es algo que escapa al estado de nuestros conocimientos, en la medida en que estamos hablando de una lengua

\footnotetext{
${ }^{27}$ El fenómeno, especialmente en relación con el sufijo *-wi, ha sido detectado y estudiado en Cerrón-Palomino (2008: II-3, § 2).Quedaría otra explicación, esta vez dentro del mismo puquina; y es que esta lengua registraba el sufijo enfático <-au> <-ao> (Adelaar y van de Kerke 2009: 141), y no es forzado pensar que una forma como *ata-aw haya podido contraerse en ataw. En cualquier caso, queda fuera de toda duda el registro de <ata> como forma radical irreductible, cosa que resulta patente en la toponimia puquina (ver nota 30).

${ }^{28} \mathrm{Y}$, para ser más precisos, adviértase que la glosa del nombre ofrecida por el jesuita cacereño resulta incompleta, ya que solo toma en cuenta el significado nuclear de <huallpa > 'dichoso (= el que tiene dicha) en guerra', dejando de lado el del modificador, quizás por considerarlo redundante: 'dichoso feliz en guerras', aunque no lo parece en 'diligente feliz en guerras'.

29 De manera que es clamorosamente ingenuo glosar <Atawwallpa>, el nombre del inca, como "gallina feliz" (Calvo Pérez 1998: 323, nota 667); pero también resulta anacrónico postular *wallpa para el proto-quechua, con el significado del ave, como lo hiciera Gary Parker, en 1969, en su reconstrucción del lexicón del proto-quechua (Parker 2013: 136).
} 
extinguida en la segunda mitad del siglo XIX, con registro gramatical y léxico inhallable, y para la cual apenas contamos con textos de naturaleza pastoral. ${ }^{30}$

Con todo, es nuestra convicción que los argumentos adelantados hasta aquí constituyen una alternativa seria de interpretación etimológica del nombre.

\section{Conclusiones.}

Tras la discusión efectuada a lo largo de las secciones precedentes, conviene que concluyamos en este punto, señalando los aspectos más relevantes de nuestra argumentación.

En primer lugar, queda claro que el nombre <Atahuallpa> es compuesto, integrado por sus componentes /ataw/ y /wallpa/, y la mejor prueba de ello es que estos fueron también antropónimos independientes (o integrantes de otros compuestos) muy recurrentes entre la nobleza incaica. Queda igualmente demostrado que el nombre del gallo/ gallina en las lenguas indígenas del hemisferio occidental sudamericano está ligado íntimamente al del última inca, tanto en su forma enteriza como recortada. Por lo demás, la inexistencia de un nombre nativo para el ave de corral es prueba suficiente, refrendada por la historia y la arqueología, de su procedencia occidental.

En segundo lugar, formalmente, el nombre del ave es de origen onomatopéyico y remedaba el del inca, ya sea celebrando sus hazañas o perpetuando su ignominia. Sin embargo, la acepción de gallina como 'cobarde', de viejo cuño español, nunca pasó al quechua ni a las demás lenguas indígenas. Tal ha sido la explicación etimológica del nombre recogida por los historiadores coloniales de labios de los propios indios, y, en tal sentido, constituye un caso típico de etimología popular, que, al ser sometida al rigor de la disciplina, no admite discusión.

En tercer lugar, hay que admitir, sin embargo, que dicha etimología es de naturaleza secundaria, en la medida en que busca explicar el fenómeno designativo a partir del conocimiento sincrónico del nombre que lo motiva y no de la historia de este. Se hacía necesario entonces averiguar la etimología primaria del mismo, indagando por su origen más allá del quechua y del aimara. De esta manera, el examen hermenéutico practicado sobre el material

\footnotetext{
${ }^{30}$ Un recurso para salvar dicha orfandad de registro, aunque solo de manera parcial y azarosa, es la consulta del léxico callahuaya, la lengua profesional de los herbolarios de Charazani (noreste de Bolivia), cuyos ancestros hablaban originariamente el puquina antes de ser quechuizados por los incas. Así, en el léxico de Girault (Guirault 1989: I, 24), encontramos, para el primer elemento, lo que podría postularse como su cognado: se trata de la entrada <ataspa>, en la que puede aislarse <ata-> (el remanente es sufijo quechua), que es glosado como "mejor", significado bastante cercano al que hemos propuesto previamente. Por lo que toca a la toponimia atribuible al puquina, otra vertiente de estudios cuyo auxilio puede invocarse, debemos señalar que resulta pródiga en el registro de nombres que conllevan la raíz $<$ ata $>$, sea como primer o segundo elemento de compuesto, según se puede ver en <Atahuaya> (Chumbivilcas, Cuzco), <Ata-mizque> (Cochabamba); y <Copo-ata> (Ilave, Puno), $<$ Mutu-ata> (La Paz), etc., por citar solo algunos de los muchos ejemplos que se registran, y sin mencionar la variante <ara>, para toda el área puquina, en los que también parecen insinuarse los significados esbozados previamente.
} 
léxico disponible, tanto en forma como en significado, autoriza a postular un origen puquina para el nombre estudiado, cuyos componentes remontarían a *ata 'señalado, elegido' y *wallpa 'diligente, aplicado', al igual que otros tantos epítetos propios de las divinidades, de los títulos nobiliarios, y de buena parte de los nombres de las instituciones del incario.

Finalmente, volviendo al nombre del ave, no está demás señalar que los españoles se habrían encargado de difundir el nombre más allá del ámbito del antiguo territorio incaico. Ya lo anunciaba el cronista enciclopédico: "es ya en todo el Perú tan común y usado, que hasta los españoles que viven entre indios llaman a la gallina, hualpa, hablando con ellos" (Cobo [1653] 1964: X, XI, 390).

\section{Referencias}

Acosta, José de. [1590] 1954. Historia natural y moral de las Indias. En Obras del P. José de Acosta, Madrid, BAE, Ediciones Atlas.

Adelaar, Willem y Simon van de Kerke. 2009. Puquina, en M. Crevels y P. Muysken (eds.), Lenguas de Bolivia. Tomo I: Ámbito andino, La Paz: Musefy Plural: 125-146.

Anónimo (Blas Valera). [1586] 2014. Arte, y vocabvlario en la lengva general del Perv llamada quichua, y en la lengua española. Editado por Rodolfo CerrónPalomino. Lima, I.R.A./ PUCP.

Anónimo. [1608] 1987. Ritos y tradiciones de Huarochirí. Versión paleográfica, interpretación fonológica y traducción al castellano de Gérald Taylor. Lima, I.F.E.A. e I.E.P.

Araníbar Zerpa, Carlos. [1615] 2015. "Índices alfabéticos" de la Nueva Corónica y buen gobierno de Guaman Poma de Ayala. Vol. IV. Lima, Biblioteca Nacional del Perú.

Bertonio, Ludovico. [1612] 1984. Vocabvlario de la lengua aymara, Cochabamba, CERES e I.F.E.A.

Betanzos, Juan de. [1551] 2015. Juan de Betanzos y el Tahuantinsuyo. Nueva edición de la Suma y narración de los Incas, Lima, Fondo Editorial PUCP. Editado por Francisco Hernández Astete y Rodolfo Cerrón-Palomino.

Brucker, Charles. 1988. L'Étimologie, Paris, Presses Universitaires de France.

Calvo Pérez, Julio. 1998. Ollantay. Edición crítica de la obra anónima quechua, Cuzco, C.E.R.A.

Cerrón-Palomino, Rodolfo. 2008. Voces del Ande: ensayos de onomástica andina, Lima, Fondo Editorial PUCP.

Cerrón-Palomino, Rodolfo. 2013a. Las lenguas de los incas: el puquina, el aimara y el quechua, Frankfurt am Main, Peter Lang.

Cerrón-Palomino, Rodolfo. 2013b. Tras las huellas del Inca Garcilaso: el lenguaje como hermenéutica en la comprensión del pasado, Boston, Latinoamericana Editores/ CELACP.

Cerrón-Palomino, Rodolfo. 2016. El lenguaje como hermenéutica en la comprensión del pasado: a propósito del puquina en la génesis del imperio incaico, Diálogo Andino, 49: 11-27. 
Cieza de León, Pedro de. [1551] 1987. Crónica del Perú. Tercera Parte. Lima: Fondo Editorial PUCP.

Cisneros, Luis Jaime. 1965. Datos fonéticos en los cronistas, Documenta, IV: 338-344.

Cobo, Bernabé. [1653] 1956. Historia del Nuevo Mundo. Obras del P. Bernabé Cobo, Madrid, BAE, Ediciones Atlas. (Tomo II).

Coello, Óscar. 2007. Atabálipa, no Atabalipa: examen de un malentendido, en M. Martos Carrera et al. (eds.), Actas del II Congreso Internacional de Lexicología y Lexicografía "Pedro Benvenutto Murrieta", Lima, Academia Peruana de la Lengua/ Universidad San Martín de Porres: 83-93.

Covarrubias, Sebastián de. [1611] 1984. Tesoro de la lengua castellana o española, Madrid/ México, Ediciones Turner.

Duviols, Pierre. 1977. Los nombres quechuas de Viracocha, supuesto 'Dios creador' de los evangelizadores, Allpanchik, 10: 53-63.

Estete, Miguel de. [1535] 1968. Noticia del Perú, Lima, Ediciones Técnicos Asociados, S.A.: Tomo I, 347-402.

Garcilaso de la Vega, Inca. [1609] 1943. Comentarios reales de los incas, Buenos Aires, Emecé Editores S.A.

Girault, Louis. 1989. Kallawaya: el idioma secreto de los incas, La Paz: UNICEF-OPS-OMS.

Gonçález Holguín, Diego. [1608] 1952. Vocabvlario de la lengva general de todo el Perv llamada lengva qquichua o del Inca, Lima, U.N.M.S.M.

Huaman Poma de Ayala, Felipe. [1615] 2015. Nueva crónica y buen gobierno, Lima, Biblioteca Nacional del Perú.

Itier, César. 1993. Estudio y comentario lingüístico, en Pierre Duviols y César Itier (eds.), Relación de antigüedades deste reyno del Piru, Cuzco, I.F.E.A./ C.E.R.A./ Bartolomé de Las Casas: 129-178.

Jerez, Francisco de. [1534] 1968. Verdadera relación de la conquista del Perú y provincia del Cuzco llamada la Nueva Castilla. Lima: Ediciones Técnicos Asociados, S.A.: Tomo I: 195-266.

Latorre, Alejandro. 2012. Atahualpa. El vergonzoso sobrenombre del último inca del Perú, Lima, Ojo Pródigo.

Molina, Cristóbal de. 1573. Relacion de las fabvlas i ritos de los Ingas, Madrid, Biblioteca Nacional, Ms. No. 3169.

Nordenskiöld, Erland. 1922. Deductions suggested by the Geographical Distribution of some Post-Columbian Words used by the Indians of $S$. America, Göthenburg, Elanders Boktryckeri Aktiebolag.

Pachacuti, Joan de Santa Cruz. [1613] 1993. Relación de antigüedades deste reyno del Piru, Cuzco, I.F.E.A./ C.E.R.A./ Bartolomé de Las Casas. (Estudio etnohistórico y lingüístico de Pierre Duviols y César Itier).

Parker, Gary J. 2013. El lexicón proto-quechua, en R. Cerrón-Palomino (ed.), Trabajos de lingüística histórica quechua, Lima, Fondo Editorial PUCP: 91144.

Rostworowski, María. 2014. Historia del Tahuantinsuyu, Lima, Instituto de Estudios Peruanos.

Santo Tomás, Domingo de. [1560] 1994. Lexicón o vocabulario de la lengua general del Perú. Edición facsimilar, transliteración y nota preliminar de Rodolfo Cerrón-Palomino. Madrid, Ediciones de Cultura Hispánica. 
Sarmiento de Gamboa, Pedro. [1572] 1960. Historia Indica, Madrid, BAE, Ediciones Atlas. (Tomo CXXXV).

Seguí, Agustín. 2006. Atahuallpa y Atabáliba, en A. Valencia (ed.), Actas del XIV Congreso Internacional de la ALFAL (Monterrey, 17-21 de octubre), Santiago de Chile, CD-ROM.

Seligmann, Linda J. 1987. The Chicken in Andean History and Myth. The Quechua Concept of Wallpa, Ethnohistory, 34, 2: 139-170.

Taylor, Gérald. 1979. Diccionario normalizado y comparativo quechua: Chachapoyas-Lamas, Paris: L'Harmattan.

Tschudi, Johann Jakob von. 1854. Travels in Peru on the Coast, in the Sierra, across the Cordilleras and the Andes into the Primeval Forests, New York, A.S. Barnes \&CO.

Zamboni, Alberto. 1988. La etimología, Madrid, Gredos. 